\title{
Peran Coaching sebagai Moderator pada Hubungan antara Pelatihan dan Penugasan Hasil Pelatihan di Tempat Kerja
}

\author{
Endah Nuraini Hamdani \\ Program Studi Magister Manajemen, Sekolah Tinggi Manajemen PPM \\ Jl. Menteng Raya No.9, Kb. Sirih, Kec. Menteng, Kota Jakarta Pusat, Jakarta, Indonesia \\ nun@ppm-manajemen.ac.id
}

Diterima: 02-12-2020

Disetujui: $28-12-2020$

Dipublikasi: 30-01-2021

\begin{abstract}
ABSTRAK
Coaching merupakan suatu metode pengembangan karyawan yang banyak digunakan akhir akhir ini untuk berbagai tujuan, seperti meningkatkan kompetensi dalam bekerja, meningkatkan kemampuan mahasiswa yang sedang belajar serta meningkatkan efektivitas pelatihan di perusahaan. Belum banyak penelitian yang menggali tentang peran coaching pada efektivitas pelatihan, oleh karenanya penelitian ini bertujuan untuk mengetahui pengaruh pelatihan di kelas (In Class Training) terhadap penugasan hasil pelatihan (Project Assigment) dan mengetahui apakah coaching berperan sebagai moderator antara pelatihan di kelas (In Class Training) dengan penugasan hasil pelatihan (Project Assigment). Pendekatan utama dalam penelitian ini menggunakan pendekatan kuantitatif yaitu data yang digunakan berupa angka dan dianalisis secara kuatitatif. Data penelitian diambil dari hasil penilaian pada penyelenggataan pelatihan MDP. Jumlah data yang diperoleh pada penelitian ini sebanyak 131 peserta. Adapun analisis yang digunakan untuk pengolahan data adalah Moderate Regression Analysis (MRA). Hasil analisa menggunakan MRA menunjukkan bahwa coaching berperan sebagai variabel Quasi moderator artinya coaching bersama sama dengan In Class Training menghasilkan peningkatan kemampuan mengerjakan project assignment (PA) dengan lebih baik. Kemampuan mengerjakan project assignment meliputi kemampuan dan membuat laporan PA serta menjajikan dalam bentuk presentasi.
\end{abstract}

Kata Kunci:

Coaching, Moderate Regression Analysis (MRA), Pengembangan karyawan.

\begin{abstract}
Coaching is an employee development method that is widely used lately for various purposes, such as increasing competence at work, increasing the ability of students who are learning and increasing the effectiveness of training in companies. Not many studies have explored the role of coaching in the effectiveness of training, therefore this study aims to determine the effect of in-class training on the implementation of training results (project assignment) and to find out whether coaching acts as a moderator between in-class training by implementing the training results (Project Assignment). The main approach in this study using a quantitative approach, namely the data used in the form of numbers and analyzed quantitatively. The research data was taken from the results of the assessment of the MDP training. The amount of data obtained in this study was 131 participants. The analysis used for data processing is Moderate Regression Analysis (MRA). The results of the analysis using MRA show that coaching acts as a moderator Quasi variabel, meaning that coaching together with In Class Training results in an increase in the ability to do a better project assignment (PA). The ability to do project assignments includes the ability to make PA reports and make presentations.
\end{abstract}

Keywords:

Coaching, Moderate Regression Analysis (MRA), Development of Employee 


\section{PENDAHULUAN}

Sumber daya manusia (SDM) merupakan modal terpenting dalam organisasi bisnis. Setiap organinisasi memerlukan sumber daya manusia yang bisa diandalkan untuk menggerakkan roda kegiatan dalam perusahaan. Perusahaan harus melakukan proses pengelolaan yang baik agar mampu memilih, mengembangkan serta memelihara sumber daya manusianya. Menurut Dessler, 2013 proses pengelolaan sumber daya manusia meliputi tahap tahap melakukan analisis pekerjaan, perencanaan kebutuhan tenaga kerja, pemilihan calon karyawan, pelatihan calon karyawan, pengelolaan gaji, penyediaan insentif, menilai kinerja, komunikasi, pelatihan dan pengembangan, pembentukan komitmen karyawan. Penelitian ini memfokuskan tentang pengembangan dan pelatihan karyawan dalam organisasi.

Dalam lingkungan yang selalu berubah, organisasi menghadapi berbagai tantangan seperti angkatan kerja terus berubah, kebutuhan dari pemberi kerja berubah sehingga sumber daya manusia harus selalu menyesuaikan. Pada masa sekarang kompetisi antar organisasi sangat ketat, persoalan inovasi menjadi penentu organisasi agar tetap bertahan dan berkembang. Sehubungan dengan hal tersebut SDM harus selalu dikembangkan selaras dengan pengembangan perusahaan. Ketika pemimpin dipromosikan ke level yang lebih tinggi, mereka menghadapi tantangan serius. Sehingga banyak yang gagal dalam mencapai tujuan (Martin 2015) atau kinerjanya tidak tercapai.

Pengembangan SDM dapat dilakukan dengan berbagai macam upaya seperti pelatihan, coaching dan mentoring. Khusus pengembangan dalam bidang manajerial, banyak organisasi yang menggunakan pendekatan melalui pelatihan dan coaching yang dikemas dalam disain pelatihan yang yang sering disebut dengan Management Development Program (MDP).

Coaching adalah suatu bentuk pengembangan dimana coach (pelatih) mendukung coachee (pembelajar) untuk mencapai tujuan pribadi atau organisasi melalui arahan dan bimbingan. Tujuan diselenggarakan program MDP untuk meningkatkan kemampuan manajerial bagi karyawan yang akan menduduki jabatan struktural (sebagai pemimpin). Untuk lebih menjamin tercapainya sasaran pelatihan maka tidak sekedar pelatihan dalam kelas namun juga dilengkapi dengan penerapan di tempat kerja. Dalam proses membantu para karyawan menerapkan konsep yang dipelajari dalam pelatihan, digunakan metode coaching.

Praktek penyelenggaraan coaching dilakukan untuk berbagai macam tujuan, seperti untuk membantu karyawan memahami menjalani pekerjaannya, karyawan memahami cara menerapkan konsep yang dipelajari, menyelesaikan masalah yang dihadapi dll. Pada kenyataannya coaching tidak selalu membawa hasil yang baik, banyak keluhan organisasi yang merasa sudah mengeluarkan banyak biaya dan meluangkan waktu untuk pelaksanaan coaching 
namun masih belum dapat menghasilkan peningkatan kemampuan SDM yang signifikan. Hasil penelitian Dwi et al. (2016) menujukkan pelaksanaan coaching tidak berpengaruh terhadap kemampuan menyelesaikan masalah karyawan.

Dalam penelitian sejauh yang diketahui, belum ada yang mengkaitkan antara coaching dan in class training dan penerapan pelatihan di tempat kerja. Bagaimana peran coaching terhadap hubungan antara pelatihan di kelas (in Class Training) terhadap project assignment apakah sebagai moderator atau mediator adalah malah yang akan dicari jawabnya pada penelitian ini.

\section{Rumusan Masalah}

1. Apakah ada pengaruh pelatihan di kelas (In Class Training) terhadap penugasan hasil pelatihan (Project Assigment)

2. Apakah coaching berperan sebagai moderator antara pelatihan di kelas (In Class Training) dengan penugasan hasil pelatihan (Project Assigment)

\section{Tujuan Penelitian}

1. Mengetahui pengaruh pelatihan di kelas (In Class Training) terhadap penugasan hasil pelatihan (Project Assigment)

2. Mengetahui apakah coaching berperan sebagai moderator antara pelatihan di kelas (In Class Training) dengan penugasan hasil pelatihan (Project Assigment)

\section{TINJAUAN TEORI}

Managerial coaching adalah one on one meeting yang dipimpin oleh manajer untuk membantu karyawan dalam mengembangkan kompetensinya dan mencapai kinerja yang lebih tinggi dengan memberikan umpan balik yang terfokus, dorongan, dan meningkatkan kesadaran (Hellman, 2009). Menurut Mosca et al. (2010), coaching merupakan intervensi yang bertujuan untuk meningkatkan kinerja serta mengembangkan kompetensi tertentu. Sedangkan menurut Cummings (2008), coaching adalah upaya meningkatan kemampuan individu untuk menetapkan dan mencapai tujuan, meningkatkan hubungan interpersonal, menangani konflik ataupun menunjukkan gaya kepemimpinan tertentu. Dari berbagai definisi tersebut di atas dapat disimpulkan bahwa coaching adalah suatu cara atau metode guna memperbaiki dan meningkatkan kemampuan karyawan baik kemampuan teknikal, interpersonal maupun manajerial sehingga dapat mencapai sasaran kerjanya. 
Menurut Utrilla et al. (2015) berdasarkan hasil penelitiannya didapatkan bahwa coaching merupakan metoda yang cukup penting yang dapat mendukung tidak hanya kinerja kerja pegawai, namun juga kin organisasi itu sendiri. Menurut McCracken \& Heaton (2012) menyatakan pentingnya coaching bagi para pegawai dan juga organisasi dan dilihat sebagai instrument bagi pengembangan karir pegawai. Coaching dipandang bagai suatu metode yang efektif guna merespon kebutuhan dan tuntutan tugas yang terus berubah dan semakin berkembang (Sherman \& Freas, 2004) dan juga sangat efektif guna melakukan koreksi dan pengembangan kinerja bagi pekerja (Gravina \& Siers, 2011).

Manfaat lain coaching tidak hanya digunakan di kegiatan manajerial tetapi juga dalam kegiatan kampus. Seperti yang disampaikan oleh Inggris Le Roux (2018), coaching membantu menyelesaikan masalah yang dihadapi para mahasiswa. Coaching manajerial berpengaruh terhadap perilaku karyawan dan kinerja penjualan, tetapi tidak ada efek moderasi yang ditemukan. Model pengukuran dan kausal menunjukkan invarian bagi karyawan, manajerial coaching akan memberikan kontribusi untuk kinerja karyawan (Pousa et al., 2017).

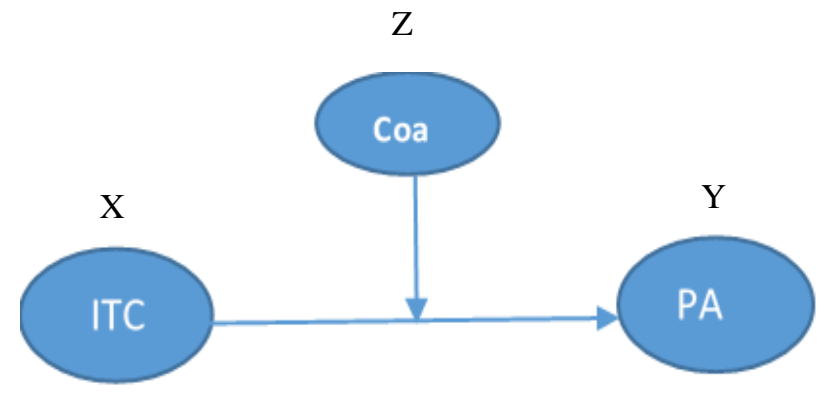

Gambar 1. Model penelitian

Dalam model penelitian tersebut terdapat 3 variabel yaitu In Class Training (X), Coaching (Z) dan Project Assigment (Y). Diskripsi operasional dari masing-masing variabel diuraikan indikator dan pengukuran sebagai berikut.:

Variabel X: In Class Training (pelatihan di kelas).

Indikator: Prestasi selama di dalam kelas yang meliputi penilaian test akhir dan partisipasi yang dilakukan oleh instruktur.

Pengukuran: Penilaian menggunakan angka dengan range 0 sampai dengan 100

\section{Variabel Z: Coaching}

Indikator: Penilaian oleh coach internal dan coach eksternal yang meliputi kesiapan saat coaching, kemampuan mendeteksi dan menganalisis masalah, kemampuan mengatasi masalah, keinginan berkontribusi untuk organisasi dan usaha untuk mencapai hasil. 
Pengukuran: Penilaian menggunakan angka dengan range 0 sampai dengan 100

Variabel Y: Project Assigment

Indikator: Penilaian presentasi oleh atasan dan trainer/coach yang meliputi:

1. Organisasi presentasi

2. Kejelasan penyajian

3. Tehnik dan gaya presentasi

4. Berkomunikasi dengan efektif

5. Kematangan sikap

Penilaian laporan oleh atasan dan trainer/coach yang meliputi:

1. Dampak terhadap organisasi

2. Tingkat inovasi proyek

3. Analisis masalah

4. Implementability

5. Pencapaian hasil

Pengukuran: Penilaian menggunakan angka dengan range 0 sampai dengan 100.

\section{METODE RISET}

Pendekatan utama dalam penelitian ini menggunakan pendekatan kuantitatif yaitu data yang digunakan berupa angka dan dianalisis secara kuantitatif. Data penelitian diambil dari hasil penilaian pada penyelenggaraan pelatihan MDP. Pelatihan MDP dirancang untuk peningkatan kemampuan manajerial dengan sasaran agar peserta mampu menerapkan konsep yang dipelajari selama pelatihan di tempat kerja. Adapun rancangan pelatihan terdiri dari pelatihan di kelas (in class training), coaching dan penugasan hasil pelatihan (project assignment).

Dalam rancangan program MDP tersebut coaching ditujukan untuk membantu peserta dalam menerapkan konsep yang dipelajari di kelas pada pekerjaan sehari-hari. Coaching dilakukan sebanyak 2 kali pertemuan masing-masing 1 jam. Coaching dilakukan oleh internal coach yaitu atasan peserta pelatihan yang menguasai bisnis perusahaan dan external coach yaitu pengajar atau instruktur yang menguasai sistematika PA. kedua coach mengarahkan agar peserta dapat menuliskan perbaikan proses di tempat kerjanya dengan menggunakan konsep yang dipelajari selama di kelas.

Sampel yang digunakan dalam penelitian ini diambil secara purposive yaitu data yang memenuhi kriteria yang telah ditetapkan (Sakaran, 2010). kriteria yang digunakan untuk 
penetapan sample adalah karyawan yang mengikuti pelatihan MDP yang bertujuan agar karyawan mampu menerapkan hasil pelatihan. Karyawan yang mengikuti pelatihan, selanjutnya disebut dengan peserta pelatihan. Adapun rancangan pelatihan yang dilakukan terdiri atas pelatihan di kelas (in class training), coaching dan penugasan hasil pelatihan (project assignment). Jumlah sampel yang telah terkumpul dalam penelitian ini diperoleh sebanyak 131 hasil penilaian peserta pelatihan MDP.

Obyek penelitian ini adalah pelatihan MDP yang diselenggarakan pada lembaga pelatihan untuk berbagai macam perusahaan. Hasil penilaian yang menunjukkan prestasi peserta yang mengikuti pelatihan tersebut diambil dan digunakan sebagai bahan analisis. Penilaian dilakukan kepada peserta pelatihan MDP yang meliputi penilaian selama mengikuti pelatihan di kelas, pada saat coaching dan pada saat Presentasi penugasan hasil pelatihan.

Untuk mendapatkan data tersebut, peneliti telah menghubungi pihak penyelenggara pelatihan dan meminta ijin dengan surat yang ditujukan kepada kepala divisi Jasa Pengembangan Organisasi, PPM-Manajemen. Pengolahan data pada penelitian ini menggunakan alat analisis Moderate Regression Analysis (MRA). Variabel moderating adalah variabel independen yang akan memperkuat atau memperlemah hubungan antara variabel independen lainnya terhadap variabel dependen.

Penilaian peserta MDP yang terdiri atas nilai In Class Training (ITC), Coaching dan Project Assignment (PA) diolah menggunakan software SPPS untuk menguji apakah variabel tersebut merupakan variabel moderator. Urutan pengujian dilakukan ITC terhadap PA, Coaching terhadap PA dan ITC \& coaching terhadap PA. Dari hasil pengujian tersebut dihasilkan 3 (tiga) persamaan regresi dengan rumusan sebagai berikut:

(01) $\mathrm{Yi}=\alpha+\mathrm{Bi} \mathrm{Xi}+\varrho$

(02) $\mathrm{Yi}=\alpha+\mathrm{Bi} \mathrm{Xi}+\mathrm{B} 2 \mathrm{Zi}+\mathrm{Q}$

(03) $\mathrm{Yi}=\alpha+\mathrm{Bi} \mathrm{Xi}+\mathrm{B} 2 \mathrm{Zi}+\mathrm{B} 3 \mathrm{Xi} * \mathrm{Zi}+\varrho$

Selanjutnya dilakukan Analisa berdasar ketentuan sebagai berikut: jika persamaan (02) dan (03) tidak berbeda secara signifikan B1 $02=\mathrm{B} 103$ dan B2 $02=\mathrm{B} 203$ dimana B3 = 0 dan B2 \# 0, maka Z bukanlah variabel moderator tetapi sebagai variabel predictor. Jika persamaan 01 dan 02 tidak berbeda, tetapi berbeda dengan persamaan 03 dimana B2 = 0 dan B3 \# 0 maka variabel $\mathrm{Z}$ adalah pure moderator. Jika persamaan 01,02 dan 03 berbeda satu sama lain dimana B2 \# B3 \#0 maka variabel Z merupakan variabel quasi moderator. (Sharma et al., 1981). 


\section{HASIL PENELITIAN DAN PEMBAHASAN}

Hasil pengolahan data kuantitatif menggunakan sofrware SPSS menunjukkan gambar 2 sebagai berikut: data menyebar pada garis diagonal dan mengikuti garis diagonal atau histogramnya menunjukkan distribusi normal yang artinya model regresi memenuhi asumsi normalitas.

Uji heteroskedastisitas dalam penelitian ini menunjukkan bahwa plot data tersebar kurang merata, hal tersebut diduga karena uji tersebut dilakukan secara bersamaan untuk data ITC, Coaching dan Project Assigment dimana pada uji regresi ITC tidak signifikan. Setelah data ITC dikeluarkan dihasilkan gambar 5 hasil uji heteroskedasitas 2 yang menunjukkan penyebaran lebih luas yang menunjukkan semakin tidak terdapat heteroskedasitas.

Hasil pengujian yang dilakukan menggunakan software SPSS menunjukkan hasil perhitungan VIF diperoleh angka 1,137 atau lebih kecil 10 artinya tidak terjadi multikolinearitas. Sedangkan perhitungan Toleransi diperoleh angkan 0,880 atau lebih besar dari 0,10 artinya tidak terjadi multikolinearitas.

Pengolahan data menggunakan MRA ini dilakukan dalam 3 tahap analisa regresi yaitu menguji hubungan antara In Class Training (ITC) dengan Project Assigment (PA), Coaching dengan PA dan ITC bersama Coaching dengan PA. Di bawah ini diuraikan hasil dari masingmasing analisa regresi. Hasil analisa regresi dari hubungan antara ITC dengan PA, menunjukkan bahwa B $($ ITC $)=0,035$. Sehingga terbentuk persamaan sebagai berikut: $Y_{1}=\alpha$ $+0,035 \mathrm{X}_{1}+\varrho \rightarrow(\mathrm{O} 1)$.

Hasil analisa regresi dari hubungan antara ITC dan coaching dengan PA, menunjukkan bahwa B $($ ITC $)=0,042$ dan B $($ coaching $)=0,194$. Sehingga terbentuk persamaan sebagai berikut: $\mathrm{Y}_{1}=\alpha+0,042 \mathrm{X}_{1}+0,194 \mathrm{Z}_{1}+\varrho \rightarrow(\mathrm{O} 2)$

Hasil analisa regresi dari hubungan antara ITC dan coaching dengan PA, menunjukkan bahwa B $($ ITC $)=0,042 ; \mathrm{B}($ coaching $)=0,194 ; \mathrm{B}($ ITCX coaching $) \mathrm{n}=0,0008$. Sehingga terbentuk persamaan sebagai berikut: $\mathrm{Y}_{1}=\alpha+0,042 \mathrm{X}_{1}+0,194 \mathrm{Z}_{1}+0,008 \mathrm{X} 1 * \mathrm{Z} 1+\mathrm{Q} \rightarrow$ (O3)

Hasil pengujian variabel moderator menggunakan metode MRA, menunjukkan terdapat tiga persamaan sebagai berikut:

$$
\begin{aligned}
& (\mathrm{O} 1) \mathrm{Y}_{1}=\alpha+0,035 \mathrm{X}_{1}+\varrho \\
& (\mathrm{O} 2) \mathrm{Y}_{1}=\alpha+0,042 \mathrm{X}_{1}+0,194 \mathrm{Z}_{1}+\varrho \\
& (\mathrm{O} 3) \mathrm{Y}_{1}=\alpha+0,042 \mathrm{X}_{1}+0,194 \mathrm{Z}_{1}+0,008 \mathrm{X}_{1} * \mathrm{Z}_{1}+\varrho
\end{aligned}
$$


Mengacu pada penjelasan analisis data: Jika persamaan (02) dan (03) tidak berbeda secara signifikan $\mathrm{B} 1(02)=\mathrm{B} 1(03)$ dan $\mathrm{B} 2(02)=\mathrm{B} 2(03)$ dimana $\mathrm{B} 3=0$ dan $\mathrm{B} 2 \#$, maka $\mathrm{Z}$ bukanlah variabel moderator tetapi sebagai variabel predictor.

Dari persamaan (02) dan (03) menunjukkan berbeda secara signifikan B1 (02) = B1(03) $=0,042$ dan $\mathrm{B} 2(02)=\mathrm{B} 2(03)=0,194$ dimana $\mathrm{B} 3 \neq 0$ dan $\mathrm{B} 2 \neq 0$, maka $\mathrm{Z}$ bukan variabel predictor melainkan variabel moderator. Sedangkan jika persamaan (01 dan 02) tidak berbeda, tetapi berbeda dengan persamaan (03) dimana B2 = 0 dan B3 \# 0 maka variabel $\mathrm{Z}$ adalah pure moderator. Persamaan (01) menunjukkan persamaan dengan (02), tetapi berbeda dengan (03) dimana $\mathrm{B} 2 \neq 0$ dan $\mathrm{B} 3=0,004$ maka $\mathrm{Z}$ bukan merupakan variabel pure moderator. Jika persamaan (01), (02) dan (03) berbeda satu sama lain dimana B2 \# B3 \#0, maka variabel $\mathrm{Z}$ merupakan variabel quasi moderator. Persamaan (01), (02), dan (03) berbeda satu sama lain dimana $\mathrm{B} 2=0.194, \mathrm{~B} 3=0,008$ atau $\mathrm{B} 2 \mathrm{~B} 3 \mathrm{0}$, maka variabel $\mathrm{Z}$ merupakan variabel quasi moderator.

Hasil analisa menggunakan MRA menunjukkan bahwa coaching berperan sebagai variabel Quasi moderator pada hubungan antara ITC dengan PA. Coaching yang dilakukan oleh instruktur membantu peserta yang telah selesai mengikuti pelatihan dalam menerapkan apa yang telah dipelajari untuk diterapkan di tempat kerja. Sedangkan coaching yang dilakukan atasan ditempat kerja dapat mengarahkan peserta pelatihan dalam menentukan masalah yang relevan dan bermanfaat untuk perusahaan. Senada dengan definisi yang diungkapkan Hellman (2009) Managerial coaching adalah one on one meeting yang dipimpin oleh manajer untuk membantu karyawan dalam mengembangkan kompetensinya dan mencapai kinerja yang lebih tinggi dengan memberikan umpan balik yang terfokus, dorongan, dan meningkatkan kesadaran.

Jika ditinjau dari hasil penelitian bahwa peran coaching dapat menguatkan pelatihan untuk menghasilkan kemampuan yang lebih baik dalan mengerjakan penugasan, maka hal tersebut berkaitan dengan siapa yang bertugas sebagai coach. Coach yang melakukan coaching terdiri atas pengajar pemberi materi selama pelatihan dan atasan langsung sebagai coach eksternal. Jadi kualitas coach memang mempunyai pemahaman yang baik tentang penugasan yang diberikan kepada coachee. Hal tersebut sesuai dengan penelitian Mihiotis \& Argirou (2016) yang menyatakan bahwa coaching yang sukses dipengaruhi oleh kualitas pelatih yaitu yang memiliki pemahaman yang baik tentang coaching, serta aktif melakukan coaching.

Demikian juga seperti hasil penelitian Terblanche et al. (2017) yang menyatakan bahwa keberhasilan coaching ditentukan oleh kecocokan disain dengan coach dg coachee, penetapan tujuan, lokasi coaching, serta keterlibatkan manajer lini, mentor dan tim pemimpin. Dalam 
penelitian ini juga digunakan coach yang sudah dikenal oleh coachee sebelum mengerjakan penugasan yaitu pemberi materi selama pelatihan di kelas. Selain itu juga dilibatkan atasan langsung untuk dijadikan coach internal.

Pelatihan terbukti mampu menambah pengetahuan seseorang sehingga mempunyai alat analisis untuk mengidentifikasi dan menyelesaikan masalah yang terjadi di unit kerjanya. Hal inilah yang membuat proses coaching menjadi lebih mudah dan terarah sehingga PA selesai dengan hasil baik.

\section{KESIMPULAN DAN SARAN}

Penelitian ini ditujukan untuk mengetahui apakah coaching berperan sebagai moderator antara pelatihan di kelas (In Class Training) dengan penugasan hasil pelatihan (Project Assigment). Hasil analisa menggunakan MRA menunjukkan bahwa coaching berperan sebagai variabel Quasi moderator artinya coaching bersama sama dengan In Class Training (pelatihan di kelas) akan menghasilkan peningkatan kemampuan mengerjakan project assignment (PA) dengan lebih baik yang meliputi kemampuan dan membuat laporan PA serta menjajikan dalam bentuk presentasi.

Dalam penelitian ini ditunjukkan bahwa hanya melakukan pelatihan di kelas saja, peserta pelatihan akan kesulitan dalam mengerjakan PA. Demikian juga peserta yang hanya menerima coaching tanpa didahului dengan pelatihan di kelas, akan menyulitkan proses coaching sehingga tidak dapat menghasilkan prestasi PA yang optimal. Pelatihan di kelas dan coaching akan saling melengkapi membentuk kemampuan menghasilkan PA lebah baik.

Untuk meningkatkan kemampuan peserta pelatihan dalam penugasan hasil pelatihan sebaiknya penyelenggara pelatihan perlu melengkapi dengan mengadakan coaching bagi peserta. Coaching sebaiknya dilakukan oleh instruktur dan atasan langsung setelah peserta pelatihan selesai mengikuti pelatihan di kelas. 


\section{DAFTAR PUSTAKA}

Cummings, T. (2008). Organization Development and Change. In Dynamics of Organizational Change and Learning. https://doi.org/10.1002/9780470753408.ch2

Dwi, D., Rahmah, N., \& Fahmie, A. (2016). Pengaruh Pelatihan Coaching TerhadapKemampuan Pemecahan Masalah pada Supervisor PT X Kalimantan Timur. $\begin{array}{llll}\text { Jurnal Intervensi Psikologi, 263-284. } & \text { 8(2), }\end{array}$ https://media.neliti.com/media/publications/101970-ID-pengaruh-pelatihan-coachingterhadap-kem.pdf

Gravina, N. E., \& Siers, B. P. (2011). Square Pegs and Round Holes: Ruminations on the Relationship Between Performance Appraisal and Performance Management. Journal of Organizational Behavior Management, 277-287. https://doi.org/10.1080/01608061.2011.619418

Hellman, K. (2009). Sales Coaching: Making the Great Leap from Sales Manager to Sales Coach. Journal of Business \& Industrial Marketing, 24(7). https://doi.org/10.1108/jbim.2009.08024gae.001

Le Roux, I. (2018). Coaching as support for postgraduate students: A case study. SA Journal of Human Resource Management, 16, 1-7. https://doi.org/10.4102/sajhrm.v16i0.939

Martin, J. (2015). Ascending to the C-suite. New York: Mc Kinsey\& Company

McCracken, M., \& Heaton, N. (2012). From "tucked away" to "joined at the hip": Understanding evolving relationships within the HRBP model in a regional energy company. Human Resource Management Journal, 182-198. https://doi.org/10.1111/j.1748-8583.2010.00150.x

Mihiotis, A., \& Argirou, N. (2016). Coaching: from challenge to opportunity. Journal of Management Development, 35(4), 448-463. https://doi.org/10.1108/JMD-10-2014-0139

Mosca, J. B., Fazzari, A., \& Buzza, J. (2010). Coaching To Win: A Systematic Approach To Achieving Productivity Through Coaching. Journal of Business \& Economics Research (JBER), 8(5), 115-130. https://doi.org/10.19030/jber.v8i5.724

Pousa, C., Mathieu, A., \& Trépanier, C. (2017). Managing frontline employee performance through coaching: does selling experience matter? International Journal of Bank Marketing, 35(2), 220-240. https://doi.org/10.1108/IJBM-01-2016-0005

Santoso, S. (2001). Buku Latihan SPSS Statistik Parametrik. Jakarta: PT Elex Media Komputindo.

Santoso, S. (2015). Menguasai Statistik Multivariat. Jakarta: PT Elex Media Komputindo. 
Sekaran, U. \&. (2017). Research Method for Business A Skill Building Approach. United Kingdom: John Wiley \& sons LTD.

Sharma, S., Durand, R. M., \& Gur-Arie, O. (1981). Identification and Analysis of Moderator Variabels. Journal of Marketing Research, XVIII, 291-300. https://doi.org/10.1177/002224378101800303

Terblanche, N. H. D., Albertyn, R. M., \& Van Coller-Peter, S. (2017). Designing a coaching intervention to support leaders promoted into senior positions. SA Journal of Human Resource Management, 15(0), 1-10. https://doi.org/10.4102/sajhrm.v15i0.842

Utrilla, P. N. C., Grande, F. A., \& Lorenzo, D. (2015). The effects of coaching in employees and organizational performance: The Spanish Case. Intangible Capital, 11(2), 166-189. https://doi.org/10.3926/ic.586 